\title{
Participants who 'eat like a King in the Morning' have lower Cholesterol concentrations
}

\author{
Mah Lentjes ${ }^{1}$, A. A. Mulligan ${ }^{1}$, A. A. Welch ${ }^{2}$, A. Bhaniani ${ }^{1}$, R. N. Luben ${ }^{1}$ and K. T. Khaw ${ }^{3}$ \\ ${ }^{1}$ University of Cambridge, Department of Public Health \& Primary Care, Cambridge CBI 8RN, ${ }^{2}$ University of East Anglia, \\ Department of Population Health \& Primary care, Norwich Medical School, Norwich NR4 7TJ, ${ }^{3}$ University of Cambridge, \\ Clinical Gerontology Unit, Addenbrooke's Hospital, Cambridge CB2 2QQ, UK
}

"Eat breakfast like a king, lunch like a prince, and dinner like a pauper" is a much heard quotation, although the evidence for this is uncertain. Meal frequency ${ }^{(1)}$ and breakfast consumption ${ }^{(2)}$ have been associated with lower serum cholesterol and reduced rate of weight gain respectively in the Norfolk cohort of the European Prospective Investigation into Cancer (EPIC-Norfolk). However, the association between time of day of maximum energy consumption in relation to serum cholesterol concentrations was not previously studied.

The EPIC-Norfolk study started in 1993 and had 25,639 men and women, aged 40-79, who attended a health examination. Weight, height and blood samples were taken by a nurse and participants received instructions on completing a 7-day diet diary (7dDD) ${ }^{(3)}$. We excluded nightshift workers, leaving 25,295 for analysis. For every diary day, energy intake was summed and re-categorised into: morning (M), afternoon (A) and evening (E) and calculated as a proportion of the whole day. Participants' individual diary days were scored depending whether most energy was consumed in the M, A or E. The median of the scores across days determined the type of eater a participant was (91\% provided 7 days of DD). Differences between M, A and E eaters in continuous variables were tested using Kruskal-Wallis, and if significant, followed by Mann-Whitney test; proportional variables tested with Chi-squared test. Differences in cholesterol concentrations were tested using ANOVA, adjusted for sex, age, smoking, social class, physical activity and body mass index (BMI).

The majority of participants $(72 \%)$ consumed most of their energy in the evening. Those who consumed the highest energy intake in the morning had significantly higher total daily energy intake. Among men, M-eaters had a higher proportion of smokers, manual occupation and were more physically active. After adjustment for sex and confounders, cholesterol concentrations for M-eaters were $5.90 \mathrm{mmol} / \mathrm{L}(95 \% \mathrm{CI}: 5.79,6.00)$, which was $0.29 \mathrm{mmol} / \mathrm{L}$ lower $(95 \% \mathrm{CI}:-0.40,-0.19)$ compared to A- and E-eaters.

\begin{tabular}{|c|c|c|c|c|c|c|c|c|c|c|c|c|c|c|}
\hline \multirow{3}{*}{$\frac{\text { Time of highest energy intake }}{n(\%)}$} & \multicolumn{6}{|c|}{ Men $(n=11,393)$} & \multirow{3}{*}{$P$} & \multicolumn{6}{|c|}{ Women $(n=13,902)$} & \multirow[b]{2}{*}{$P$} \\
\hline & \multicolumn{2}{|c|}{ Morning } & \multicolumn{2}{|c|}{ Afternoon } & \multicolumn{2}{|c|}{ Evening } & & \multicolumn{2}{|c|}{ Morning } & \multicolumn{2}{|c|}{ Afternoon } & \multicolumn{2}{|c|}{ Evening } & \\
\hline & 308 & 3 & 2,977 & 26 & 8,108 & 71 & & 178 & 1 & 3,586 & 26 & 10,138 & 73 & \\
\hline Age $(y)$ & 59 & 9 & 61 & 10 & 59 & 9 & $\#$ & 58 & 10 & 62 & 9 & 57 & 9 & \# \\
\hline Energy $(\mathrm{MJ} / \mathrm{d})$ & 9.9 & 2.8 & 9.3 & 2.3 & 9.5 & 2.2 & $\# \$$ & 7.5 & 2.2 & 7.0 & 1.7 & 7.2 & 1.6 & \# \\
\hline $\operatorname{BMI}\left(\mathrm{kg} / \mathrm{m}^{2}\right)$ & 26.3 & 3.2 & 26.6 & 3.4 & 26.5 & 3.3 & ns & 26.3 & 4.8 & 26.6 & 4.5 & 26.1 & 4.3 & \\
\hline Active $(\%)$ & 51 & & 42 & & 45 & & $\# \$$ & 36 & & 33 & & 39 & & \\
\hline Social class, manual (\%) & 56 & & 42 & & 40 & & $\# \$$ & 39 & & 38 & & 39 & & $\mathrm{~ns}$ \\
\hline Smoker $(\%)$ & 14 & & 10 & & 13 & & $\#$ & 14 & & 9 & & 13 & & \\
\hline Cholesterol $(\mathrm{mmol} / \mathrm{L})$ & 5.7 & 1.0 & 6.0 & 1.1 & 6.1 & 1.1 & $\# \$$ & 6.1 & 1.3 & 6.5 & 1.2 & 6.3 & 1.2 & $\#$ \\
\hline
\end{tabular}

Continuous variables are mean and standard deviation.

Significant differences $(P<0.05)$ between M\&A (\#), M\&E $(\$)$; ns = no overall difference (Kruskal-Wallis).

Having the highest energy intake in the morning was associated with lower cholesterol concentrations, a reduction similar to what can be achieved with dietary advice ${ }^{(4)}$; however, residual confounding cannot be excluded and the proportion of M-eaters was limited. Moreover, possible interactions with meal frequency will require further study.

1. Titan SM, Bingham S, Welch A, et al. (2001) BMJ (Clinical research ed.) 323, 1286-8.

2. Purslow LR, Sandhu MS, Forouhi N, et al. (2008) Am J Epidemiol 167, 188-92.

3. Bingham SA, Welch AA, McTaggart A, et al. (2001) Public Health Nutr 4, 847-58.

4. Thompson R (2003) Cochrane Database, CD001366. 